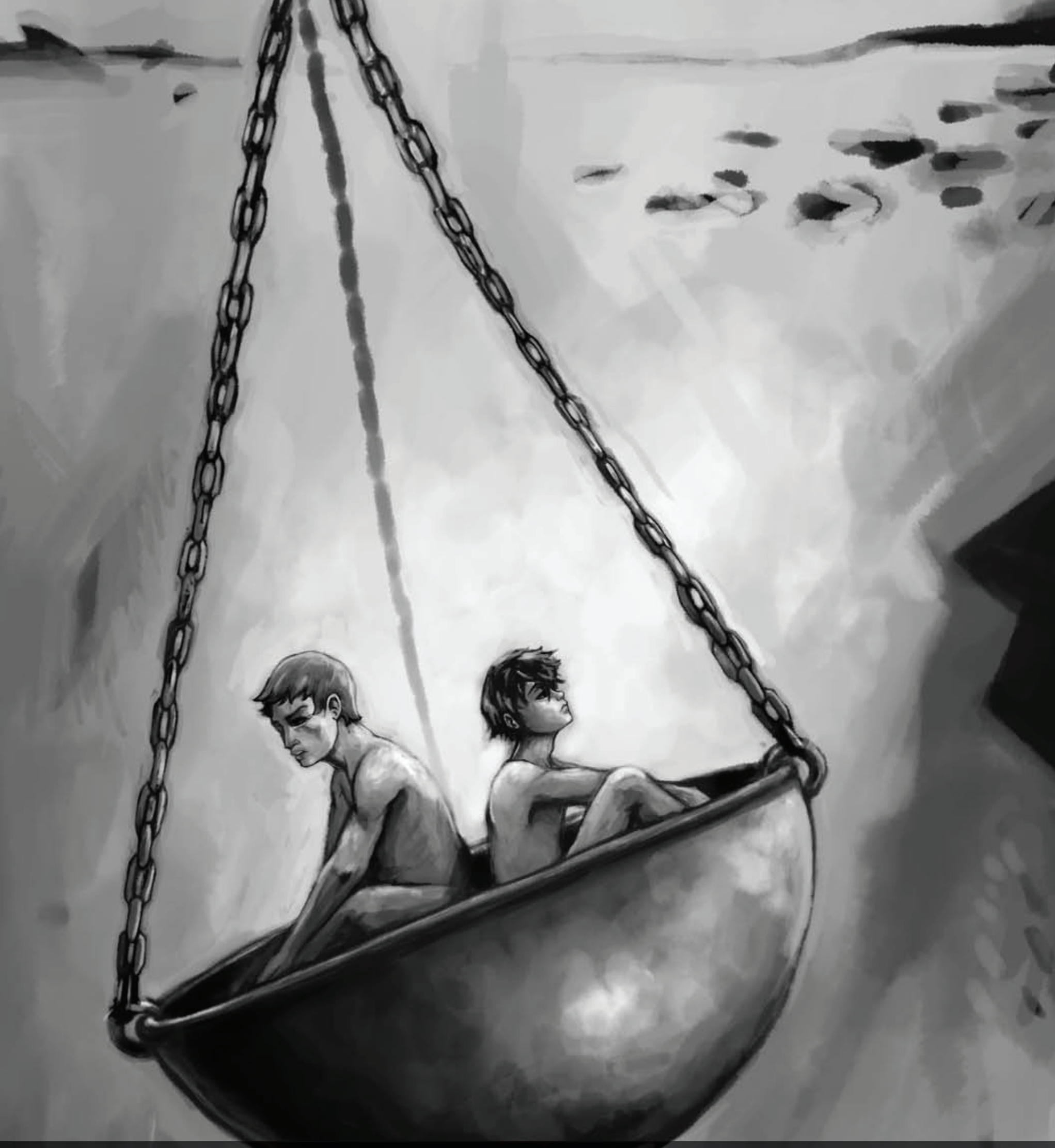

Responsabilidad penal del empleador por delitos cometidos en la empresa por sus subordinados 



\section{Responsabilidad penal del empleador por delitos cometidos en la empresa por sus subordinados}

\author{
Criminal liability of the employer for crimes \\ committed by their subordinates.
}

\author{
Walter Jose Saavedra Troncoso (Colombia) \\ waltersaavedra84@hotmail.com \\ Institución Universitaria Politécnico Grancolombiano
}

Responsabilidade penal do empregador por delitos cometidos na empresa por seus subordinados.

\section{Resumen}

En este trabajo se realiza un estudio sobre la responsabilidad penal del empresario por los actos al margen de la ley que cometen sus subordinados. Se busca aclarar si el empresario debe responder penalmente cuando el delito es cometido por un subordinado en ejercicio de sus funciones o cuando este actúa a nombre de la empresa ya sea valiéndose de la información que manejan, del grado de responsabilidad o de la confianza.

Por esta razón concentraremos nuestra atención en analizar la responsabilidad penal por la omisión de controles del empresario hacia el subordinado, exponiendo la problemática que se deriva de la posición de garante del primero en las operaciones empresariales.

\begin{abstract}
The paper analyzes the criminal liability of employers for the acts, regardless of the law committed by their subordinate employees. Investigates whether the employer should respond when the criminal offense is committed by a subordinate in the exercise of his duties or when acting on behalf of the company, either using the information it handles, the degree of responsibility or trust.

For this reason, our attention investigates criminal liability for failure to control by the employer to the subordinate, exposing the problems arising from the position of guarantor of the first business operations.
\end{abstract}

\section{Resumo}

Em este trabalho realiza-se um estúdio sobre a responsabilidade penal do empresário pelos atos à margem da lei que cometem os seus subordinados. Procura-se aclarar se o empresário deve responder penalmente quando o delito é cometido por um subordinado em exercício de suas funções ou quando este age no nome da empresa já seja valendo-se da informação que manejam, do grau de responsabilidade ou da confiança.

Por esta razão concentraremos nossa atenção em analisar a responsabilidade penal pela omissão de controles do empresário para com o subordinado, expondo a problemática que se deriva da posição de garante do primeiro nas operações empresariais. 
Palabras claves: Responsabilidad penal, empresa, subordinados.

Keywords: Criminal liability, company, employees

subordinate.
Palavras chave: Responsabilidade penal, empresa, subordinados.

\section{Para citar este artículo/ To cite this article/ Para citar este artigo}

Saveedra, Walter (2012). Responsabilidad penal del empleador por delitos cometidos en la empresa por sus subordinados. Panorama, VII (12), 69 - 96. 


\section{Introducción}

Es importante desarrollar un estudio sobre la responsabilidad penal empresarial por el impacto y auge de esta nueva modalidad delincuencial que afecta el patrimonio de muchas personas, entre las cuales se encuentran los socios, los empleados, los consumidores y los acreedores.

Toda empresa implica riesgos y oportunidades, al igual que la condición de empresario, dentro de los riesgos existen los considerados normales, propios del giro normal de los negocios, como son las fluctuaciones del mercado, el impacto de políticas económicas, también se encuentran los hechos o aconteceres que escapan de todo control o previsión de toda persona, como son los casos que se clasifican dentro de las figuras de caso fortuito o fuerza mayor.

Sin embargo, la falta de los controles en los procesos empresariales o corporativos permiten, en muchas ocasiones, acciones delictivas por parte de los subordinados, en este aspecto es importante determinar el grado de responsabilidad del empresario cuando el subordinado, que como un delincuente interno, se aprovecha de sus conocimientos sobre el funcionamiento de la empresa, para realizar su ilícito burlando todos los controles.

Al penalizar a los miembros de los órganos de dirección de la empresa, se debe considerar cada caso en particular, siendo necesario demostrar que se han realizado acuerdos antijurídicos o que no aplicaron los mecanismos de control, esta situación vislumbra si la omisión de controles favorece la comisión del delito y causa un daño, siendo importante determinar si el ataque al patrimonio se pudo evitar con la aplicación de mecanismos de control en forma acertada y eficaz, lo que permite concluir si existe o no, una responsabilidad del empresario en la comisión del delito.

La responsabilidad penal del empresario por los delitos cometidos por los subordinados, ya sea por acción directa o valiéndose del giro normal de los negocios, es una modalidad de delincuencia presente en las empresas donde algunos empleados abusan de; la confianza recibida; la información que obtienen y manejan, o de la autoridad que les confiere el cargo, facultades que usan para cometer actos delictivos, planificados y ejecutados a la sombra de la buena imagen de la empresa, comprometiendo el nombre de la organización y del empresario, quien puede llegar a ser declarado culpable y obligado a responder penalmente en casos muy particulares.

Por lo anterior se hace necesario establecer una diferencia entre los delitos cometidos a través de una organización delincuencial encubierta por un manto corporativo, el cual enfrenta acciones que van desde la investigación de los hechos, implicando el acceso a información reservada, hasta la intervención que puede generar el levantamiento del velo corporativo, encontrando que la teoría del velo corporativo ha generado interesantes debates académicos y jurisprudenciales en Colombia (Vanegas Franco, Alejandro, 2010)

1 La Corte Constitucional en Sentencia C- 299 de 1998 establece en desarrollo del artículo 55 del Código Sustantivo del Trabajo que: "El contrato de trabajo, como todos los contratos, debe ejecutarse de buena fe y, por consiguiente, obliga no sólo a lo que en él se expresa sino a todas las cosas que emanan precisamente de la naturaleza de la relación jurídica o que por la ley pertenecen a ella". 
Otro aspecto que busca esclarecer la jurisprudencia, relacionado con el tema de estudio, es la autoría, la participación y el grado de responsabilidad en los delitos cometidos por algunos subordinados, valiéndose de su posición dentro de la organización corporativa, la cual funciona en forma adecuada a los parámetros legales en cuanto a su estructura, organización y mecanismos de control. Esta situación exige una claridad sobre la autoría y la participación del empresario y los subordinados en la ejecución del acto delictivo. Sobre el particular, las altas corporaciones se han pronunciado en reiteradas jurisprudencias buscando dar claridad sobre la autoría, la coautoría y la participación.

En este sentido la Corte Suprema de Justicia ha reiterado este concepto en los fallos de casación pronunciados el 11 de julio de 2002, el 24 de abril de 2003 y el 18 de febrero de 2004, al dejar en claro que el actual desarrollo dogmático y jurisprudencial ha sido orientado a reconocer como característica de la denominada coautoría impropia, que cada uno de los sujetos intervinientes en el hecho punible no ejecutan en forma integral y material la conducta típica, pero facilitan su realización al contribuir en forma objetiva a la consecución del resultado común en la que los participantes en el ilícito pueden dominar los hechos de acuerdo a una división del trabajo, acordado previamente, ya sea mediante acuerdo expresos a tácitos².

Los delitos que cometen los empresarios o los subordinados pueden alcanzar grandes dimensiones, generan graves consecuencias en la economía nacional, como ocurrió en el año 2008 con el tema de las pirámides y de la organización DMG (Tiempo, 2008) que produjo multitudinarias protestas en diferentes ciudades del país durante los meses de octubre, noviembre y diciembre de ese año, causando una grave crisis social, controlada por las autoridades públicas en forma rápida, evitando mayores consecuencias sociales y económicas.

Estos delitos requieren precisar si es procedente imputar responsabilidad penal al empresario y a sus subordinados, el principio de responsabilidad individual, que rige en el Derecho Penal colombiano, ha sido establecido con el fin de evitar incurrir en formas de responsabilidad penal objetiva.

Reyna Alfaro, L.M. (2009) manifiesta que se debe revisar este aspecto desde su conveniencia político criminal, buscando imputar dentro de las estructuras empresariales no solo al sujeto individualmente responsable del hecho punible, además de analizar la posibilidad de procesar a los directivos de la empresa que coadyuvan o participan en la comisión del ilícito, encontrando casos donde la responsabilidad recae en cabeza del directivo debido a la deficiente organización empresarial que facilita la consumación del ilícito. El concepto de la responsabilidad objetiva lo desarrolla Günter Jakobs (Jakobs, 1997) quien estudia esta responsabilidad desde la óptica de los roles, al igual que Feijoo, quien amplia el concepto, al aplicarlo en los delitos económicos sociales (Feijoo Sánchez, 2009).

2 El acuerdo puede ser previo o concurrente con la comisión del hecho, sin que para la atribución de responsabilidad resulte indispensable que cada interviniente lleve a cabo o ejecute la totalidad del supuesto fáctico contenido en el tipo o que sólo deba responder por el aporte realizado y desconectado del plan común, pues en tal caso, una teoría de naturaleza objetivo formal, por ende, excesivamente restrictiva, sin duda muy respetuosa del denominado principio de legalidad estricto, no logra explicar la autoría mediata ni la coautoría, como fenómenos expresamente reconocidos en el derecho positivo actual (art. 29 de la Ley 599 de 2000), los cuales a pesar de no haber sido normativamente previstos en la anterior codificación, no pueden dar lugar a entender que no fueron objeto de consideración o que el sistema construyó un concepto de autor distinto del dogmáticamente establecido; como también aludió a la teoría del dominio del hecho para resolver problemas de autoría mediata. Corte Suprema de Justicia, Sala de Casación, 18 de febrero de 2004, radicación 17252. 
Desde el punto de vista jurisprudencial, en Colombia la Corte Constitucional en la Sentencia C-843-99, explicó que la Constitución y la ley no se oponen a la posibilidad de encontrar responsabilidad penal en una persona jurídica. Posteriormente mediante la Sentencia C - 558 de 2004, declara exequible el artículo 65 de la Ley 600 de 2000, (Demanda de Inconstitucionalidad, 2004) al igual que la Sentencia C-843 de 1999, todas son decisiones orientadas a precisar la responsabilidad penal de las personas jurídicas, acorde a lo establecido en el artículo 91 del C.P.P.

El delito cometido al interior de una empresa hace que el juicio de responsabilidad penal debe recaer sobre las personas naturales, una vez hallados responsables se impone una pena accesoria, la cual puede ser la cancelación o suspensión de la personería jurídica del ente que ha sido utilizado total o parcialmente para la comisión de los delitos para aquellos eventos donde existe alguna clase de responsabilidad corporativa, tal como lo establece el artículo 91 del C.P.P.

En Colombia es importante estudiar los criterios dogmáticos necesarios para establecer si un empresario es o no, responsable por delitos que se comentan en desarrollo del objeto social de la empresa, especialmente cuando son realizados por sus subordinados. Estos criterios constituyen las figuras jurídicas de la autoría, la participación, la comisión, ya sea por omisión o por acción, la imputación objetiva, además que permite individualizar la responsabilidad penal en cada caso particular (Nieto Marin, 2008) o tal vez será (Nieto Marín Martín, 2008).

El presente estudio aborda el tema desde lo general a lo particular, señala la importancia de establecer una clara regulación de la responsabilidad penal del empresario por delitos cometidos por los subordinados, ya sea por su mala cultura corporativa o sus defectos administrativos, dentro de las que se puede incluir la omisión de controles y la posición de garante del empresario (Bacigalupo, 2005).

La importancia del tema radica en el impacto y auge de una nueva modalidad de delito, deteriorando la buena imagen de la empresa, esto genera pérdidas o crisis, que afectan, no solo a la víctima del ilícito, ya que los perjuicios se extienden a personas inocentes que se encuentran vinculadas, de una u otra forma, con la organización empresarial, siendo éste el caso de los subordinados que actúan de buena fe exenta de culpa.

El avance en la tecnología de la información, al igual que su influencia en casi todas las áreas de la vida social, hace surgir una serie de comportamientos que antes eran impensables, en algunos casos su tipificación es difícil, no se puede recurrir a la analogía, la cual es prohibida por el principio de legalidad (Acurio del Pino, 2010).

Los miembros de los órganos de dirección de la empresa corren el riesgo de ser penalizados, ya sea por su omisión o su acción, sea por realizar acuerdos antijurídicos o por no aplicar los mecanismos de control, favoreciendo en esta forma la comisión del delito, para el caso de la omisión, es indispensable determinar si el ataque al patrimonio pudo ser evitado al aplicar mecanismos de control en forma acertada y eficaz, en el caso de la acción del empresario es necesario determinar el grado de participación y autoría en el delito. 
La acción criminal de los subordinados puede ser el resultado de

- Una empresa criminal.

- La acción del empresario que utiliza al empleado (acción mediática) sin que el subordinado tenga conocimiento de la comisión del ilícito.

- La acción del empresario utilizando al empleado (acción mediática) con el conocimiento que el subordinado tiene de la comisión del delito.

- La omisión de controles, que deriva en la responsabilidad del empresario como posición de garante.

En el caso de la empresa criminal encontramos tres variantes: la básica, la sistemática y la extendida, la participación en la comisión del delito es el resultado de un propósito criminal común, se trata de una coautoría material impropia, en la que media la división de trabajo, las acciones de algunos participantes en el acto criminal son aparentemente intrascendentes o atípicos, pero son actos que garantizan el fin criminal.

Otro sector de la doctrina entiende que tanto el sujeto que desde la cima de la maquinaria organizada de poder imparte la orden delictiva, cuanto el individuo que la ejecuta materialmente, con dolo y plena responsabilidad, encuadran ambos en la categoría de la coautoría (Jescheck, 1995, p.611).

En el caso del empresario que utiliza los empleados para lograr el fin ilícito, incurre en una acción mediática, pues aunque el subordinado desconoce las consecuencias de su actuación, se aprecia cómo su participación en la ejecución del acto lo convierte en parte esencial en la comisión del ilícito, y aunque haya actuado de buena fe, las consecuencias jurídicas derivadas del delito lo pueden convertir en cómplice del mismo.

La anterior situación es diferente cuando el empresario se asocia con sus subordinados para cometer un delito, se trata de una conducta típica, calificada como concierto para delinquir, modalidad delictiva compleja, pues en algunos casos los delincuentes logran la impunidad de sus actos debido a la complejidad de la acción ilícita 3 .

El empresario puede verse comprometido en la comisión del delito como resultado de la omisión en los controles que debe realizar al interior la empresa; esta omisión se debe establecer si obedece a una política corporativa deficiente, a una ineficaz cultura empresarial o procesos sin control ni aseguramiento de la calidad que facilitan la consumación del delito.

3 El artículo 186 del C. P. colombiano establece: Concierto para delinquir. Modificado. Ley 365 de 1997, art. 8. Cuando varias personas se concierten con el fin de cometer delitos, cada una de ellas será penada, por ese solo hecho, con prisión de tres (3) a seis (6) años. La pena se aumentará del doble al triple para quienes organicen, fomenten, promuevan, dirijan, encabecen, constituyan o financien el concierto o la asociación para delinquir. 
El presente estudio también profundiza la posición de garante que tienen los directivos de la empresa, al no vigilar ni alizar el perfil personal o profesional de sus empleados en cargos de manejo de información contable o de propiedad intelectual e industrial; lo que demuestra...la importancia de determinar el grado de responsabilidad que tiene el empresario sobre las consecuencias derivadas del delito.

\section{Antecedentes de la responsabilidad penal del empresario por delitos cometidos por sus subordinados}

La responsabilidad penal del empresario por los delitos cometidos por sus subordinados, se encuentra incluida en la legislación de algunos países de Europa, como una modalidad de delito (Sánchez Sánchez, 2005). En Colombia la tipificación de las conductas punibles de los empresarios tienen un tratamiento similar al europeo, de acuerdo a la norma, la jurisprudencia y la doctrina que existen sobre el particular. La legislación colombiana busca establecer la responsabilidad del empresario dentro de una nueva concepción de la responsabilidad penal del empleador.

El modelo de imputación penal a los empresarios, que existente en la actualidad, es propio de las estructuras sociales del siglo XX, totalmente diferente a la división del trabajo del siglo XXI; hoy asistimos a una verdadera revolución en las comunicaciones y las tecnologías, situación que genera una modificación en las relaciones empresariales, originando nuevas formas de establecer relaciones laborales, porque el panorama de la acción y la ejecución no dependen de la capacidad de decisión del superior, el dependiente o subordinado de menor categoría, sino de quien goza del poder par aplicar el control en todos los procesos, gracias a las tecnologías que hábilmente manejan, permitiendo la comisión de fraudes.

En este aspecto, es necesario tipificar en forma clara toda conducta de los subordinados que se oriente a burlar u omitir los controles, con el fin de obtener un provecho ilícito.

El fenómeno presente en el sector financiero, al igual que las defraudaciones cometidas con la complicidad de algunos empleados, no constituye una conducta empresarial, situación que hace complejo el tema de la responsabilidad del empresario por su acción o su omisión en los controles y su posición de garante.

En este aspecto son varios que ya se han presentado al suplantarse la identidad de una persona y lograr la apertura de una cuenta bancaria, la aprobación de una tarjeta de crédito y o créditos de libre inversión, defraudando al banco y mancillando el nombre de una persona inocente que sufre la suplantación de identidad; estos delitos no son posibles sin la complicidad interna, debido a los estrictos controles que existen en las entidades financieras, en las cuales no solo dejan registro de la huellas dactilares, además de las fotografías que toman a la persona que hace la apertura de la cuenta ${ }^{4}$.

4 Corte Suprema de Justicia, Sala de Casación Penal, Sentencia 31324 del 21 de octubre de 2009, no casa el recurso extraordinario interpuestos por los implicados en delitos financieros y de suplantación de identidad. 
En las legislaciones europeas e el primer modelo clásico penal para legislar este tipo de delitos, se encuentra en Francia, Portugal y Alemania, reforma de 1994 introdujo como criterio suficiente una función dirigente en el seno de la persona moral. El alcance de ese concepto, a primera vista restringido, se encuentra en lo establecido en el derecho alemán, muy diferente al derecho español ya que en Alemania se considera una clase de responsabilidad más amplia: la ley sobre las Ordnungswidrigkeiten (art. 130) donde se establece la omisión de control, de organización y de vigilancia como infracción específica, permitiendo que un órgano de dirección o el representante legal puedan resultar culpables de la infracción cometida por un empleado de rango inferior, en ese caso se analiza si el órgano de dirección, el empresario o representante legal, podían haber impedido o disminuido el riesgo de la comisión de la infracción al haber actuado en forma diligente (Reyes) .

La forma como se compromete la responsabilidad del empleador por los actos de los subordinados que actúan en ejercicio de sus funciones, está claramente definida para algunos casos concretos en el Código Civil colombiano, en el cual este concepto establece que también tiene esta responsabilidad la persona jurídica que tiene que indemnizar los daños que causen los funcionarios o agentes en el ejercicio de sus funciones (Tamayo Jaramillo, 1999).

Aun existiendo el sustento constitucional de la responsabilidad penal del empresario y de la empresa (Nieto Martín, 2008) no existe claridad sobre la norma aplicable en los eventos de la responsabilidad penal de los empresarios debido a los actos de los subordinados; este aspecto implica definir en cada caso concreto la autoría y la participación en la comisión del ilícito por parte del empresario, al igual que el grado de responsabilidad por la acción o la omisión de las funciones.

El artículo 29 del Código Penal colombiano establece que el autor es la persona que realiza la conducta punible, por sí mismo o utilizando a otro como instrumento, y la diferencia de los coautores, que según el Código, son: "en quienes media un acuerdo común, actúan con división del trabajo criminal atendiendo a la importancia del aporte, al respecto se establece:

Es autor quien realice la conducta punible por sí mismo o utilizando a otro como instrumento. Son coautores los que, mediando un acuerdo común, actúan con división del trabajo criminal atendiendo la importancia del aporte.

También es autor quien actúa como miembro u órgano de representación autorizado o de hecho de una persona jurídica, de un ente colectivo sin tal atributo, o de una persona natural cuya representación voluntaria se detente, y realiza la conducta punible, aunque los elementos especiales que fundamentan la penalidad de la figura punible respectiva no concurran en él, pero sí en la persona o ente colectivo representado.

El autor en sus diversas modalidades incurrirá en la pena prevista para la conducta punible” (Colombia, 2011).

El concepto unitario de autor ha sido revaluado casi en su totalidad por su íntimo nexo con el concepto peligrosista, dentro de este concepto unitario se desarrollan dos corrientes: a) la posición de carácter formal, donde se considera que toda persona partícipe del hecho delicitivo es autor de la misma, y b) la posición de carácter 
material, en la que se acepta la igualdad en el aporte causal de todos los intervinientes y establece su marco punitivo (Navas Corona, 2002).

Esta segunda postura admite la clasificación de la autoría, encontrando el autor por incitación, el autor por determinación, el autor inmediato, el autor mediato, el autor por apoyo, el autor por colaboración, siendo este último el que prima en el Código Penal colombiano (Díaz y García Conlledo, 2009).

La Corte Suprema de Justicia sostiene que en la autoría mediata el ejecutor material no responde penalmente porque solo es un instrumento que es utilizado por el verdadero y único autor (Sentencia Única Instancia, 2000). La ausencia de responsabilidad en este caso se fundamenta en que el ejecutor material (instrumento) actúa atípica, justificada o inculpablemente, lo cual puede ocurrir por coacción insuperable, error invencible o por haber sido utilizado como inimputable.

La autoría material, intelectual, individual, consorciada, la complicidad y el encubrimiento, constituyen fuentes clásicas de responsabilidad penal, pero son insuficientes para castigar a los responsables de dirigir empresas criminales, por el hecho de no participar directamente en la ejecución del acto; por su parte, en la legislación penal colombiana se incluye como responsables de los delitos a los autores mediatos en su condición de líderes de actividades organizadas, con un amplio margen de responsabilidad en cabeza del empresario quien con su conducta pasiva o activa, facilita la consumación del delito (Sentencia Única Instancia, 2000).

\section{Responsabilidad penal del empresario en Colombia, derivada de las acciones ilícitas de sus subordinados}

El desarrollo de las tecnologías y la evolución acelerada de las comunicaciones, modifica las tradicionales formas de división del trabajo; por esta razón se debe considerar que la actual empresa moderna es amplia y de compleja organización, lo que permite generar acciones con fines delictivos, sin que las mismas sean fácilmente detectables, o castigables. Por ello la impunidad está a la orden del día.

El actual panorama presenta tres características específicas en las nuevas formas de integración o división del trabajo, las cuales por su carácter ejecutivo, el manejo y control de información al igual que el poder, permiten tomar decisiones en forma rápida.

El modelo de imputación basado en la teoría del delito, la antijuridicidad y la tipicidad, puede convertirse en un reto que no permite establecer el grado de responsabilidad del empresario debido a las acciones delictivas de algunos subordinados. Esta situación impone el desafío de responder al nuevo esquema de producción, organización y desarrollo de las empresas en un nuevo panorama empresarial, donde se producen rápidas modificaciones por la velocidad de la información y las comunicaciones, al igual que la evolución de los mercados, las relaciones labores y comerciales, las tecnologías de punta, Ilevando consigo cambios sustanciales en la sociedad, derivadas de nuevas formas de relación que dificultan la imputación. 
En este panorama, las nuevas modalidades delictivas le obligan a las organizaciones desarrollar una implementación eficaz de los tradicionales modelos de imputación, para que ofrezcan soluciones dentro de un marco de respeto de las garantías constitucionales y legales.

En la legislación penal colombiana, la noción de autoría relaciona categorías como la autoría mediata y la coautoría (Márquez Cárdenas, 2009), ya que en esta se afirma que la autoría y la participación son las dos formas de intervenir una conducta calificada como punible. La autoría se concreta a partir de la ejecución del verbo rector descrito en el tipo penal, con sus diferentes formas o modalidades como son: la mediata, la inmediata, la coautoría y por representación, para el caso de la participación, se consideran dos formas específicas: la complicidad y la determinación. (Corona, 2002). A continuación se explican brevemente estas nociones para centrar el tema en el caso de la omisión de controles y la responsabilidad penal del empresario derivada de su posición de garante.

\section{La empresa criminal y la responsabilidad penal del empresario}

Encontramos que en los eventos donde la empresa criminal es producto de la acción del empresario —quien con el propósito de cometer el delito desarrolla en forma individual o asociada, una empresa con fines ilícitos- constituye la sociedad comercial con el lleno de todas las formalidades legales(registra la razón social ante la Cámara de Comercio, obtiene el Registro Único Tributario (RUT) ante la Dirección de Impuestos y Aduanas Nacionales de Colombia (Dian), cumple con las exigencias legales que debe cumplir la empresa para su funcionamiento), con el fin de que estos actos le permitan convencer a sus víctimas sobre la legalidad de su empresa, y motivándolo a negociar con una empresa "seria", que le traerá beneficios. No obstante esta aparente "legalidad" permite burlar la acción de la justicia penal al actuar bajo el amparo de una persona jurídica.

La modalidad delictiva desarrollada mediante una empresa constituida legalmente, facilita que se confunda la defraudación con el incumplimiento del contrato, porque en muchos casos garantiza la impunidad del empresario. Un ejemplo de esta afirmación se encuentra en la mayoría de empresas criminales creadas para fines ilícitos, dedicadas a la compraventa de vehículos. En estas organizaciones comerciales, los empresarios brindan la posibilidad de adquirir un taxi con amplias facilidades de pago, pero el único propósito es estafar a los incautos5.

La modalidad de delito implica celebrar un contrato de compraventa, amparado con la existencia de un establecimiento de comercio, el cual funciona con el lleno de los requisitos legales, lo cual motiva que los casos sean considerados no como un delito, sino como un incumplimiento del contrato; por esta razón se registra un incremento en esta clase de fraudes. La prensa registra varias notas como la del 31 de julio de 2009 (Periódico El Tiempo, 2009), donde se relacionan capturas efectuadas por los agentes del CTI en Cúcuta al poner a órdenes de la justicia penal a la señora Luz Alexandra Atehortúa Higuita ( elmundo.com, 2009) responsable de la estafa de 277 taxistas por una cuantía de \$3.779 millones de pesos. En este caso un juez de control de garantías ordenó poner en la cárcel del

5 El presidente de Asociación Colombiana de Comerciantes de Autopartes, Asopartes, Tulio Zuloaga reveló un informe donde se informa que en lo corrido del 2012 existen más de 1100 denuncias por estafas, efectuadas en concesionarios de garaje. El informe revela que cerca del $70 \%$ de estas denuncias se registran en Bogotá (Dávila, 2012). 
buen pastor a la "empresaria", quien fue condenada por los cargos de estafa agravada, concierto para delinquir, enriquecimiento ilícito, falsedad y abuso de confianza.

La empresa criminal es desarrollada por un empresario o un grupo de personas, los cuales se dedican a realizar acciones coordinadas para obtener un fin ilícito mediante un acuerdo de voluntades o concierto para delinquir, tal como lo estable el artículo 340 de la parte especial del Código Penal colombiano. Dicha situación faculta determinar si existe, por esta vía, una coautoría impropia, como mecanismo presente al lado de la coautoría, p para poder penar a todo interviniente en la ejecución del delito, así realice actos atípicos (Corte Suprema de Justicia, Sala de Casación Penal, 2009).

La Corte Suprema de Justicia desarrolla la tesis de la autoría mediata mediante aparatos organizados de poder, a partir de la teoría de Roxin', quien considera al hombre de atrás, el que mueve los hilos, quien da la orden de ejecutar el delito con la seguridad de que algún miembro de esa estructura la cumpla, éste último actúa como autor inmediato fungible (Sentencia, 2007) la cual indica cómo el autor inmediato es remplazable, sustituible y responde como autor material del hecho punible (Sentencia, 2008).

\begin{abstract}
Roxin pretende sistematizar, desarrollar y reconstruir las categorías dogmáticas de tipicidad, antijuridicidad y culpabilidad bajo el prisma de su función político criminal en una suerte de sistema abierto en orden a la resolución de los problemas que la realidad presenta, sin que se pueda tomar como una renuncia al contenido de las categorías dogmáticas elaboradas hasta el momento, su pretensión será complementar las mismas y perfeccionarlas. Así, por ejemplo, la categoría de la imputación objetiva elaborada por Roxin no sustituirá a la causalidad, sino que la complementará para perfeccionar la imputación en el marco del tipo objetivo ${ }^{7}$.
\end{abstract}

El artículo 36 del Código Penal colombiano establece la conducta dolosa cuando el agente conoce el hecho punible y quiere su realización, lo mismo cuando la acepta previéndola al menos como posible (Consejo Superior de la Judicatura, 2011). En este aspecto, el profesor Tamayo Jaramillo considera que el dolo penal y el dolo civil son exactos, con la salvedad que en algunas oportunidades el dolo civil constituye un ilícito civil al causar un daño a terceros, mientras que esa conducta no constituya un delito penal, así no lo tenga contemplado el legislador (Tamayo Jaramillo, 1999).

No obstante, la Fiscalía General de la Nación, por medio de sus delegados, en esta clase de delitos, no puede garantizar que se haga justicia, esto obedece a diferentes factores entre los que sobresale: a) la presión que sufre de los órganos de control que le exigen cumplir con las estadísticas, haciendo que sus actuaciones sean contrarias a la jurisprudencia; y b) la legislación, que presiona la realización de acuerdos o conciliaciones, los cuales en muchas oportunidades no son favorables para la víctima, pues se trata de casos donde lejos de quebrantarse el poder del estado, éste permanece incólume (Gómez Velásquez, 2009).

6 Claus Roxin analiza el tema de la delimitación y el contenido de las categorías del delito, encontrando que hoy no se puede dividir en forma clara el injusto y la culpabilidad en lo externo y lo interno, en elementos subjetivos y objetivos, como se hacía en el sistema clásico de Beling, en el cual la culpabilidad no es una categoría descriptiva.

7 Arias Eibe, M.J. (2006). Funcionalismo penal moderado o teleológico valorativo versus funcionalismo normativo radical, Santiago de Compostela: Universidad de la Coruña, p. 441. 


\section{La Acción del empresario que utiliza al empleado (acción mediática) sin que el subordinado tenga conocimiento de la comisión del ilícito}

El empresario puede instrumentalizar a los subordinados, convirtiendolo en la persona que ejecuta directamente el acto delictivo, y haciendo que esta acción le reporte un beneficio directo y se constituya en la causa determinante del delito 8 . De esta forma el empresario o director de la organización empresarial al conocer las bondades del nuevo sistema penal, -puede llegar a celebrar acuerdos que le son favorables a quien delinque, o por ser beneficiario de una reducción de la pena a un mínimo- hace que se registren casos como el llamado escándalo del carrusel de la contratación, donde el ex director del Instituto de Desarrollo Urbano (IDU) es condenado a 96 meses de prisión y una multa de 14.2 salarios mínimos, los cuales no equivalen ni siquiera a 77 millones de pesos frente a un fraude que superó los 280.000 millones de pesos (www.eltiempo.com, 2011).

Casos de esta índole que ilustran el afán de despachar las investigaciones sin administrar justicia, se encuentran en grandes cantidades; por ejemplo el caso de Saludcoop donde la apropiación se hace en provecho de los directivos de la EPS, burlando toda acción penal gracias a las bondades que brinda el sistema penal colombiano. Los subordinados realizan sus labores de buena fe, entregan los informes en la forma que requiere el empresario, sin tener claridad del ilícito que se comete.

La responsabilidad penal del empresario puede presentar dificultades relativas a la individualización de la imputación. Por esto, una posible solución es orientar la investigación hacia niveles más altos, con el fin de diagnosticar y determinar la responsabilidad penal de las personas que dan origen a la acción delictiva. Estos responsables pueden ser directivos de la empresa o miembros de los órganos de dirección, señalando a los subordinados como las personas que delinquen, con el fin de lograr la impunidad del ilícito.

El hecho de valerse de los subordinados para lograr los fines ilícitos, y aprovechar que los empleados desarrollen sus labores desconociendo los fines ilícitos que persigue el empresario, como sucede en el caso de Saludcoop (Portafolio, 2011) donde ilustra la forma como los empleados cumplen de buena fe con las funciones de su cargo, sin percatarse que son parte de un engranaje criminal por desconocer que realizan acciones encaminadas a la consumación de un delito e ignorando el verdadero manejo que hace el empresario del patrimonio de la empresa. En este caso es evidente la manipulación que hace el empresario de sus subordinados. Este caso se parece al de

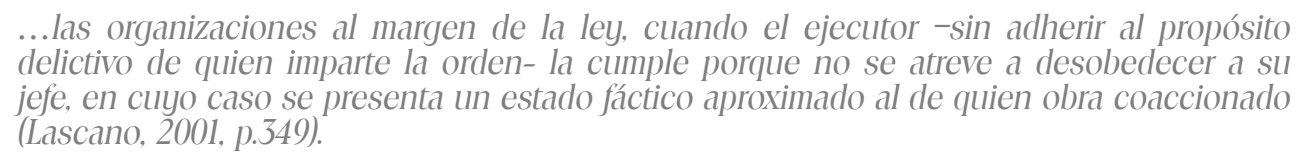

Acción del empresario que utiliza al empleado (acción mediática) con conocimiento del subordinado sobre la comisión del delito

8 La exigencia de una conducta, acción u omisión, es una condición ineludible para todas las formulaciones delictivas. En el caso de la acción, la polémica se centra en la solución de dos asuntos principales: la determinación de la naturaleza de la acción y la omisión; y la formulación de un concepto general de acción que logre comprender ambas formas de la conducta humana (Suñez Tejera, 2012). 
En este caso encontramos una modalidad donde el empresario y el subordinado actúan en forma dolosa, la razón por la cual deben responder por su delito, es porque constituyen una acción ilícita que resulta de una serie de actos coordinados entre el empresario y el subordinado. El único propósito es perfeccionar el delito y por ello, cada uno desarrolla una parte de la acción, a sabiendas del acto criminal. El subordinado no es utilizado para lograr el fin delictivo pues hace parte del delito, participando en forma voluntaria9 y con pleno conocimiento del acto ilícito(Díaz y García Conlledo, 2009).

Esta modalidad delictiva le facilita al empresario actuar con la seguridad de burlar la acción penal en el evento de ser capturado, ya que se acoge a los beneficios que ofrece el nuevo procedimiento penal, como es el caso del principio de oportunidad o mediante la conciliación con su víctima, en todo caso, se vale de las garantías constitucionales que le favorecen ${ }^{10}$.

En la comisión del ilícito es clara la responsabilidad del empresario debido a los actos de sus subordinados con los que ha realizado un acuerdo de voluntad, constituyendo así una acción delictiva llamada concierto para delinquir, en el cual siempre se busca realizar una acción que no encaje en el tipo penal, pues al no ser típica la acción, no se equipara con el delito cometido. De esta forma el empresario burla la acción de la justicia valiéndose de figuras como la conciliación, con la cual termina la investigación sin que sea acusado formalmente de cometer un delito $^{11}$. En este aspecto es importante considerar lo expuesto por el profesor Roxin al establecer que
...mientras normalmente ocurre que un interviniente, cuanto más alejado está de la víctima y de la acción típica directa, más queda relegado a la zona periférica del suceso y excluido del dominio del hecho, en estos casos ocurre, a la inversa, que la pérdida de proximidad al hecho se compensa por la medida de dominio organizativo, que va aumentando según se asciende en la escala jerárquica del aparato (Cancio Meliá, 1998).

\section{La omisión de controles y la posición de garante}

La omisión del empresario en su obligación de ejercer los controles con los cuales se evita causar daños a terceros, abre una oportunidad para que sea aprovechada por los subordinados que persiguen fines ilícitos dentro de la empresa. En este caso, al empresario le asiste la obligación de indemnizar a terceros, por el deber legal que tiene éste de estar atento en la prevención de todo acto ilícito que puedan realizar sus subordinados, y sin la posibilidad de alegar que el delito es producto de la burla de los controles existentes en la organización empresarial.

\footnotetext{
9 El Dr. Jorge Alberto Hernández Esquivel, deja en claro que: En nuestra jurisprudencia, en tres oportunidades se le ha planteado a la Corte Suprema de Justicia la posibilidad de que reconozca esta forma de autoría mediata. En la primera oportunidad lo hizo la Procuraduría en el proceso contra Carlos Castaño por la muerte del senador Cepeda perpetrada por los paramilitares; la segunda oportunidad fue en el caso "Machuca" perpetrado por miembros de la organización guerrillera Ejército de Liberación Nacional ( ELN), y en la tercera, en relación con un atentado que pretendían hacerle las FARC a un reconocido periodista; en estos casos, como presupuesto indispensable, se pretendía que se reconociera a los tres grupos al margen de la ley como verdaderas organizaciones con las características señaladas por la doctrina para que operara la autoría mediata por aparatos organizados de poder, que implica plena responsabilidad tanto para el ejecutor material como para quien da la orden o la transmite(Hernández Esquivel, 2008, p.20).

10 La Corte ha admitido que algunas garantías procesales, -y entre ellas el derecho de defensa y contradicción- no son absolutas y pueden ser limitadas por el legislador, siempre que no se vea afectado su núcleo esencial, la limitación responda a criterios de razonabilidad y proporcionalidad, y no se desconozcan otros derechos fundamentales, como puede ser el derecho a la igualdad. En todo caso, ha señalado que la función, tanto del legislador como del juez constitucional, es tratar de lograr que todos los principios y derechos que eventualmente puedan entrar en tensión a la hora de regular los términos judiciales sean garantizados en la mayor medida posible (Apelación contra Sentencia, 2011).

11 Un ejemplo es la defraudación en el sector financiero, el cual se repite como se observa desde el caso de a Caja Vocacional hasta el escándalo de las llamadas pirámides (www.semana.com, 1997).
} 
Pero si se encontrara que la omisión en los controles de la empresa son el resultado de un interés del empresario, mediante el cual facilitó la comisión del ilícito por parte de los subordinados, el empresario es responsable penalmente por su conducta dolosa Diferente es el caso de la omisión derivada de una ineficiente cultura empresarial, donde la responsabilidad puede ser culposa, porque esto exige precisar si el empresario adquiere la calidad de garante, aspecto que remite al concepto jurídico de la diligencia debida, por la ejecución de una acción realizada por el empresario. En cuanto al control y la vigilancia, se debe encaminar a prevenir cualquier fraude y no a facilitar su comisión ${ }^{12}$.

En la empresa moderna, el empresario puede ver comprometida su responsabilidad al no ejercer adecuados controles, ya sea por la delegación de funciones, por cargos de manejo y confianza o simplemente por el hecho de no contar con cláusulas y sistemas de seguridad que le impidan a sus empleados acceder a información privilegiada ${ }^{15}$.

La delegación de funciones puede constituir un mandato, facultando al subordinado para realizar algunos actos propios del giro normal de los negocios o de la actividad comercial de la empresa, pero a la vez hace que el subordinado cuente con la posibilidad de manipular los mecanismos de control.

La delegación de funciones exonera de responsabilidad al delegante, porque la responsabilidad recae y en forma exclusiva en el delegatario; siempre que la acción u omisión sean una responsabilidad exclusiva del delegatario, sin la intervención del delegante, el delegatario debe responder por el hecho propio ${ }^{14}$. Es por esto que la Corte Suprema de Justicia reitera en relación al principio de confianza que

Una de las características del mundo contemporáneo es la complejidad de las relaciones sociales y, en materia de producción de bienes o servicios, la especialización en las diferentes tareas que componen el proceso de trabajo.

No siempre el proceso de producción o comercialización es controlado por una sola persona, no pudiendo exigir a cada individuo que revise el trabajo ajeno, esto haría ineficaz la división del trabajo, es claro que uno de los soportes de las actividades de equipo con especialización funcional es la confianza entre sus miembros ${ }^{15}$ (Corte Suprema de Justicia, 2006).

12 Ello indica que la responsabilidad penal de los sujetos y agentes económicos - especialmente en el orden jerárquico, estará en correspondencia con el organigrama institucional y empresarial que comúnmente tiene cualquier sistema económico clasificado en tres niveles o escalones básicos: los obreros y empleados, los mandos intermedios y los directivos (Mejía Rodríguez, 2012).

13 Por información privilegiada se entiende aquella información a la cual solo tienen acceso directo ciertas personas, como los administradores o personal de manejo y confianza, quienes la manejan en razón de su profesión u oficio; esta información debido a su carácter confidencial, se somete a reserva debido al impacto que genera su conocimiento, porque puede ser utilizada con fines ilícitos para obtener un provecho o beneficio.

14 La Corte Constitucional. Sentencia C-233 de 2002, M.P. Álvaro Tafur Galvis establece: es pertinente recordar que el artículo 14 de la Ley 678 de 2001 señala que la autoridad judicial cuantificará el monto de la condena correspondiente atendiendo al grado de participación del agente en la producción del daño, culpa grave o dolo, a sus condiciones personales, a la valoración que haga con base en las pruebas aportadas al proceso. Es decir que contrariamente a lo expresado por el demandante no se está en presencia de una forma de responsabilidad objetiva que desconocería de manera evidente el ordenamiento superior. La Corte hace énfasis en que es precisamente la conducta del servidor público o del particular que cumple funciones públicas el objeto de análisis en el proceso de acción de repetición o de llamamiento en garantía, pues es la culpa grave o dolo lo que se examina para determinar si se le debe condenar o no, a resarcir a la administración por el pago que ella haya hecho.

15 Corte Suprema de Justicia, 2006. 
Lo anterior demuestra la importancia para el empresario y para la empresa en desarrollar un adecuado proceso de selección de personal con el fin de evitar implicaciones penales que serán atribuidas a la persona que lidera el proceso productivo o empresarial; esto es diferente a la situación del acto provocado por el mismo empresario, quien en forma dolosa, por la ausencia o deficiencia en la vigilancia, abre la posibilidad de acciones ilícitas por la deficiente cultura empresarial (Corte Suprema de Justicia , 2002). En este sentido considera la Corte que no es suficiente la simple relación de causalidad material para concluir sobre la responsabilidad penal de un procesado, ya que es necesario que la consecuencia lesiva sea obra suya (Corte Suprema de Justicia , 2002).

La división del trabajo, al igual que la complejidad de la producción o la prestación de servicios, son situaciones propias de la empresa moderna que escapan al control del empresario, quien siendo diligente en sus funciones no puede lograr un estricto control por el surgimiento de nuevos retos; esto lo obliga a desarrollar innovadores controles para minimizar todo vacío, que puede ser aprovechado por el subordinado para alcanzar fines ilícitos amparado en las funciones de su cargo ${ }^{16}$. El artículo 2341 del Código Civil, establece la obligación de indemnizar a la persona que por sí o a través de sus agentes, causa un daño a otro, en este caso quien reclama la indemnización debe demostrar el daño, el hecho intencional o culposo atribuible al demandado y la existencia del nexo causal entre ambos factores, siendo responsable el empresario, de manera penal o civilmente por quedar probado que confluyen los mencionados factores. ${ }^{17}$

La responsabilidad penal se hace más compleja mientras que en la pequeña empresa la responsabilidad del empresario es más fácil de determinar.. La organización típica de los modernos procesos productivos, conduce de una imputación jurídico penal individual a una responsabilidad organizada de los miembros de la empresa o persona jurídica (Roxin, Jakobs, Schünemann, Frisch, \& Köhler, 2000). Esta última postura busca penalizar la conducta desplegada en la organización empresarial por el empresario, quien debe responder por los hechos cometidos por sus empleados o subordinados, la responsabilidad derivada de la acción o de la omisión del empresario en el cumplimiento de sus deberes es similar al escenario en el que incurre al convertirse en gestor del acto criminal, porque esta forma se configura una autoría mediata cuando el agente realiza el tipo penal valiéndose de otra persona que actúa como instrumento, para la ejecución de la conducta consagrada en la ley penal (Márquez Cárdenas, 2009).

Un aspecto diferente se puede observar en la responsabilidad derivada de hechos aislados, que son producto del abuso de los empleados o subordinados, quienes aprovechan el grado de control, manejo de información o poder que tienen para ejecutar, decidir o incidir en el resultado de una acción ilegítima, la cual es realizada bajo el amparo de la imagen corporativa. Dicha acción genera una responsabilidad para el empresario, en los ilícitos

16 Hernández Esquivel indica que "Mayor problemática ha tenido entre nosotros el denominado dominio del hecho por dominio de la voluntad; sin embargo, algunas de sus formas han tenido mayor discusión, pues en tratándose de la coacción, la creación o aprovechamiento del error o la utilización de inimputables, tanto la jurisprudencia como la doctrina han aceptado estas formas de dominio porque las han tenido como clases de autoría mediata, englobándolas dentro de la expresión utilizada en el artículo 29 de nuestro Código Penal cuando habla de quien realice la conducta punible "utilizando a otro como instrumento", y por sobre todo porque se parte de la tradicional concepción de que el ejecutor material nunca será responsable porque ha actuado atípica o justificadamente o con ausencia de culpabilidad (Hernández Esquivel, 2008).

17 La culpa se presenta frente a una actuación marcada por la imprudencia, la negligencia o la impericia, la culpa grave significa que estos calificativos se presentaron en la conducta del agente en su mayor grado, deben estudiarse los hechos sobre los cuales recae la decisión del empleado para tomar una decisión, al igual que las circunstancias en que se produce, con el fin de establecer hasta qué punto es reprochable la conducta del agente que profirió el daño. 
cometidos por la deficiente cultura administrativa, al dejar ver la debilidad de los mecanismos o procesos de control interno de la organización empresarial y facilitando así la consumación del delito.

El empresario puede ser culpable de hechos ilícitos cometidos por la deficiente cultura corporativa ${ }^{18}$, siendo que basados en el concepto clásico, la culpabilidad del empresario es producto del defecto de la organización, el cual puede consistir en una suerte de responsabilidad imprudente, ya que se le puede reprochar la permisividad o el descuido que propició una lesión a bienes jurídicos (la muerte de un trabajador, la contaminación ambiental, la apropiación del patrimonio ajeno por parte de sus subordinados, etc.) o la falta de liderazgo al no haber organizado correctamente sus procesos de producción o de administración (Martínez Pardo, 2010). En este escenario es importante resaltar el deber objetivo de cuidado sobre el cual subyace el tipo de lo injusto del delito imprudente, se trata de un concepto normativo que indica lo qué es y lo que tiene qué hacer (o no hacer) el sujeto, además de cómo ha de proceder (Meini, 2003) para evitar que el hecho se califique como delito, cometido en forma dolosa, es decir, con plena conciencia y convencimiento de lo ilegal del acto realizado.

La doctrina fundamenta la responsabilidad en la posición de garante para el empresario, en el ámbito de la responsabilidad por el producto, llevando a considerar obligaciones jurídicas del empresario en su actividad comercial. El profesor Roxin considera que la posición de garante no puede fundamentar una infracción objetiva del deber, esta postura conlleva un rechazo a la teoría formal del deber jurídico. Es claro que no es posible asumir una infracción objetiva del deber, sin que implique una alusión al deber de cuidado (Roxin, 1997).

La posición de garante no se puede derivar de una imputación basada en la mera causalidad, es necesario que se configure un actuar previo, donde el autor debe crear un riesgo no permitido (Demetrio Crespo, 2010). En el caso de la omisión, se debe considerar que puede ser impropia si el autor y el cómplice tienen el deber legal de impedir el resultado, caso en el cual ambos ostentan la posición de garante, al respecto la Corte Suprema de Justicia considera que la posición de garante, para el cómplice, corresponde a las conductas de omisión impropia, o comisión por omisión, esto implica que no se debe exigir la posición de garante para imputar cargos al empresario que omite sus funciones (Sentencia Sala de Casación, 2003).

La posición de garante derivada del deber de vigilancia del empresario, se valora de acuerdo al riesgo propio de las funciones del cargo y la actividad empresarial, ${ }^{19}$ considerando el riesgo permitido o normal, si el riesgo se incrementa por la indeterminación de la actividad empresarial en una escala continua, sin censura, el incremento del riesgo puede generar consecuencias jurídicas cuando la actividad de la empresa enfrenta situaciones que escapan de todo control, pues genera oportunidades para la comisión de ilícitos, sin configurar una responsabilidad objetiva del empresario, derivada de su calidad de garante(Demetrio Crespo, E., 2010).

18 La cultura corporativa de control que debe existir en una organización se relaciona con: La integridad y valores éticos de sus empleados, la competencia para la acción, la filosofía administrativa y estilo de dirección, la estructura organizacional, la asignación de autoridad y responsabilidad, la Política de Recursos Humanos y los Comités de Auditoría u otros relacionados con las mermas (Muñoz Díaz, 2011).

19 La Corte Suprema de Justicia, en Segunda Instancia dentro del proceso 25.536 de 2006, Sala de Casación Penal, M. P. Dr. Álvaro Orlando Pérez Pinzón, 27 de julio de 2006, establece que la posición de garante es la situación en que se halla una persona, en virtud de la cual tiene el deber jurídico concreto de obrar para impedir que se produzca un resultado típico que es evitable. 
El subordinado que aprovecha el grado de control, manejo de información o poder que tienen para ejecutar las funciones de su cargo, al incidir en el resultado de una acción ilegítima, ejecutada bajo el amparo de la imagen corporativa, le impone a la empresa la necesidad de establecer si el empresario cumple o no, en forma estricta, con las funciones propias de su cargo, ya que la omisión constituye un factor importante que facilita la comisión del delito, haciéndolo penalmente responsable del ilícito ${ }^{20}$.

El grado de responsabilidad del empresario no solo depende del beneficio que recibe por la acción ilícita, la responsabilidad trasciende el simple concepto del lucro derivado del hecho criminal. Cuando la responsabilidad se origina en la omisión de controles, sin existir la intención de causar un daño, conseguir un lucro o un beneficio patrimonial, se debe tomar como una falta de cuidado del empresario, haciendo que sea responsable, tanto civil como penalmente por el daño causado.

La posición de garante, frente al deber de vigilancia que tiene el empresario, impone que evite toda fuente de peligro, por ser la persona que tiene el dominio sobre los subordinados y sobre las cosas; en este aspecto el artículo 1903 del Código Civil colombiano establece el deber que tienen los padres de responder por los daños causados por sus hijos, en la misma forma las autoridades deben responder por los daños que causan sus funcionarios y los empleadores respecto de los actos de sus empleados.

La posición de garante del empresario que se deriva de los hechos penales cometidos por sus subordinados, debido al poder de dar órdenes, a la parcial independencia de los miembros de la empresa, no implica que se pueda alegar una autoría mediata basada en el dominio del empresario, se hace necesario que la posición de garante se derive de una responsabilidad intensificada, que implica que no se puede justificar la responsabilidad del empresario como garante, si está basada en la dirección que tiene de la empresa, pues aceptar esta teoría es regresar al concepto del deber jurídico con la perdida de cualquier orientación material, al encontrar que la estructura organizacional de la empresa impone unos límites al poder que tiene sobre los empleados. Esto se hace claro en las grandes empresas donde el dominio personal se orienta cada vez más a un poder despersonalizado, constituyendo una dificultad para establecer el grado de responsabilidad penal del empresario a partir de su posición de garante. (Demetrio Crespo, E., 2010).

El Estatuto Civil colombiano establece la responsabilidad por el hecho ajeno, derivado de los actos realizados por las personas que se encuentran bajo su dependencia, los artículos 2346, 2347, 2348, 2349 y 2352 del Código Civil colombiano instituyen que las personas responden por el hecho ajeno de aquellos que están bajo su dependencia o cuidado. En este caso se exonera de responder a quien está llamado a hacerlo si demuestra que aún con la autoridad y el cuidado que le confiere su respectiva calidad, no había podido impedir el hecho, tal como lo establece el artículo 2347 citado (Tamayo Jaramillo, 1999).

20 La Corte Suprema de Justicia, Sala de Casación Civil, en sentencia pronunciada en el expediente No. 11001-3103-038-2001-01054-01, establece que la responsabilidad estaría vinculada a las capacidades de prevención del daño, bajo la mayor aptitud para preverlo y evitarlo con la adopción de las medidas idóneas para impedirlo a un costo menor, o sea, "(...) responde del daño aquel que se encuentra en la posición más adecuada para conducir el análisis costos-beneficios, esto es, a asegurar la conveniencia de evitar el daño comparando los costos relativos y el costo en el cual consiste el daño mismo. 
El delito que comete el subordinado gracias a la poca o nula cultura empresarial genera un daño que en principio es de carácter civil, la responsabilidad civil extracontractual se encuentra regulada por el título XXXIV del Código Civil, tanto la jurisprudencia como lo doctrina identifican tres elementos propios de esta clase de responsabilidad:

Una acción u omisión dolosa (intención de dañar) o culposa (negligencia, impericia o imprudencia).

Un perjuicio patrimonial o extra-patrimonial (el perjuicio debe ser cierto y aparecer probado, se trata de reparar el perjuicio causado y no de enriquecer a la víctima)

Un nexo de causalidad entre las dos primeras (el acreedor tiene la carga de probar la existencia de los tres elementos para que prospere su pretensión indemnizatoria, excepto en los casos en los que se presume la culpa)

La responsabilidad puede ser penal y deriva consecuencias para el empresario, al igual que para la misma empresa, al verse obligada a responder por su omisión si es el factor facilitador del resultado ilícito. En este evento, el empresario responde por el poco o inexistente control, cuando esta omisión facilita la acción ilícita, constituyendo una negligencia que genera responsabilidad penal derivada de los hechos realizados por los subordinados que se aprovechan de la poca previsión o descuido (Bonilla, 2009).

El empresario que omite métodos de control con el propósito de obtener resultados fraudulentos, con un fin predeterminado de cometer un delito, no siempre actúa solo, razón por la cual se debe establecer cuáles actos o hechos son cometidos en forma aislada, cuáles se hicieron en asocio del personal subordinado, los cuales fueron realizados en forma directa por el empresario, y cuáles de estos actos se pueden determinar como dolosos o culposos $^{21}$. La legislación penal colombiana contempla la posibilidad de responder en la calidad de garante, modalidad de responsabilidad propia de los delitos dolosos; mientras que para los culposos, el artículo 25 del C. P. no establece distinción alguna en este sentido, se entiende que la posición de garante se configura, no por la modalidad de la conducta sino por tener a su cargo la protección de un bien jurídico o la vigilancia de una fuente de riesgo (Abello Gual, 2011), situación que es aplicable al empresario que no ejecuta su labor con una adecuada cultura corporativa o empresarial, favoreciendo la comisión de ilícitos por parte de subordinados que aprovechan la falta de control para cometer el delito.

La disminución o reducción de los controles obedece a diferentes factores, ya sea por elevar la rentabilidad, pues el empresario busca minimizar costos y maximizar resultados; por sacrificar personal especializado en la vigilancia o control; o también por modificar tecnologías, adquiriendo otra de menor costo, pero que no ofrece una alta seguridad. Toda esta reducción en los costos de seguridad, lo único que propicia es una debilidad permanente

21 Para el Derecho Penal colombiano, la conducta es dolosa cuando se conocen los hechos constitutivos de la infracción y se quiere su realización; es culposa cuando el resultado no se prevé siendo previsible o habiéndose previsto, se confía en poder evitarlo. 
ante el fraude, pues estas acciones se originan por el afán de mostrar resultados a bajo costo, causando a largo plazo mayores costos de los que se pretendieron ahorrar. La obtención de rendimiento económico, al igual que la pretensión de mantener bajo control algunos riesgos específicos, genera diferentes resultados en la responsabilidad penal del empresario por delitos cometidos por los subordinados.

\section{Conclusiones}

La posición de garante del empresario, derivada de los hechos cometidos en el seno de la empresa, solo se deriva del deber de mantener bajo control determinadas fuentes de peligro, típicamente empresariales, inherentes al proceso productivo de determinadas empresas; esto constituye un deber para el empresario, en el sentido de estar atento a minimizar los riesgos y ejercer controles. Este aspecto se pueden desarrollar tres posibles hipótesis:

A. La responsabilidad del empresario derivada de su cultura empresarial. En este caso se debe precisar el grado de autoría mediata, la cual critica a la teoría formal objetiva por considerar como autor del delito al agente que ejecuta alguno o todos los elementos del tipo. Esta conceptualización es retomada por la teoría de la autoría mediata, por no ser el sujeto quien realiza de su propia mano la acción típica.

Es necesario establecer si la falta de estrictos controles facilitan el delito o si es el resultado de un plan premeditado para causar el daño y obtener el beneficio ilícito, aprovechando el descuido o negligencia del empresario. Esta hipótesis implica definir si el daño causado por la acción ilícita debe ser indemnizado o reparado, implicando consecuencias de carácter penal o civil, siendo necesario establecer el grado de responsabilidad que tiene el empresario por el daño que causa el delito cometido por sus subordinados, ${ }^{22}$ al ser el resultado de la inadecuada cultura empresarial, pero no se trata de un elemento que configure, en sentido estricto, una responsabilidad de carácter penal, en forma exclusiva.

B. La segunda hipótesis se basa en el beneficio, incremento o detrimento del patrimonio económico que recibe el empresario al ser consumado el delito. Al convertirse el beneficio en un factor para determinar la responsabilidad que tiene en la ejecución del delito - en el caso de un detrimento o incremento patrimonial originado en el abuso de confianza del subordinado que actúa en contra de los principios empresariales, amparado en el poco o nulo control de los mecanismos de vigilancia de la organización empresarial - es innegable que existe una responsabilidad del empresario por su poco cuidado, esto implica determinar el grado de responsabilidad penal o civil en cada caso particular.

22 Es la obligación de quien tiene personas bajo sus órdenes, de responder por los daños que éstos ocasionaren a terceros; es decir que (...) la responsabilidad del principal por el acto ilícito del dependiente reside en la circunstancia de que este último es un instrumento que prolonga su actividad práctica y económica; la obligación de aquél de responder por el propio hecho se hace extensiva al cometido por el subordinado, quien debe haber causado ilícita y culpablemente un daño (LópezMesa \& Félix, 2004). 
En este sentido encontramos que el artículo 1616 del Código Civil colombiano establece, en materia contractual, que solo se pagan los perjuicios directos y previsibles, si el deudor no actúa dolosamente (Tamayo Jaramillo, 1999). En ocasiones se cometen ilícitos que generan responsabilidad civil, el delito genera perjuicios patrimoniales o extra patrimoniales a un tercero, los cuales deben ser indemnizados, sin que el daño conlleve consecuencias penales (1999).

C. La tercera hipótesis respecto a la responsabilidad del empresario, se precisa a partir del grado de autoría y participación. En este aspecto existe el concepto extensivo del autor, considerado como todo aquel que interviene en el proceso causal que acaba con la producción de un hecho típico (Márquez Cárdenas, 2009), pues la responsabilidad penal del empresario se estructura a partir de la delegación de funciones en los empleados que desempeñan cargos de manejo y confianza, pero el cual al escapar a los estrictos controles, violando los mecanismos de control implementados en la empresa, de los cuales el empresario es su directo responsable, facilita la acción ilícita al no cumplir con las funciones por no estar actualizado en los avances de la tecnología que maneja o por no actuar en forma diligente o por lo menos dejar constancia de las fallas que señala en forma acertada, lo cual le exonera de su responsabilidad penal, si ha realizado lo necesario pero se enfrenta a la dificultad de no poder concretar los controles.

Los casos de negligencia, descuido, afán de presentar cifras favorables en la gestión, aún a costa de sacrificar importantes aspectos de la seguridad empresarial, derivan en una responsabilidad para el empresario que puede ser de índole civil o penal, debido al grado de autoría o participación. La manipulación de la organización empresarial con fines criminales no se puede equiparar a la creación de una organización empresarial con fines ilícitos, ya que una es la organización criminal${ }^{23}$ creada con el claro objetivo de delinquir, mientras que otra es la situación acción generada en la empresa, utilizada con fines ilícitos, ya sea por el empresario o por algunos de sus funcionarios o subordinados, que aprovechan la oportunidad de cometer el delito.

Los resultados delictivos en una organización o empresa constituida con un fin ilícito, frente a la empresa que es manipulada con objetivos delictivos, aunque son parecidos nunca serán iguales, en el segundo caso el empresario puede ser víctima del delincuente quien lo asalta en su buena fe, ya sea por el exceso de confianza, ya sea por no aplicar en forma estricta los controles o por ser burlado en las medidas de seguridad por los subordinados. En estos eventos le corresponde al director de la empresa, en su calidad de garante, por el deber que se deriva del manejo de la empresa, ser analizado en el aspecto del cuidado y la adopción de medidas de seguridad, con el fin de precisar el dominio fáctico para precisar si las decisiones aplicadas fueron acordes al riesgo y lograron prevenir o evitar el daño, siendo claro en este aspecto si los órganos de dirección tenían la posibilita delegar la responsabilidad, transmitir los correlativos deberes de garantía, con la seguridad de ser exonerado de toda culpa al estar actuando en

23 En este aspecto es importante recalcar que se considera como empresa criminal toda organización empresa criminal conformada por un número importante de personas, quienes cumplen diferentes tareas para conseguir un fin ilícito. 
forma diligente y responsable o si por el contrario, estas delegaciones o acciones son acciones que constituyen el factor que felicita el ilícito ${ }^{24}$.

La responsabilidad es más próxima a la dirección de la empresa en tanto sea menos localizable la fuente de peligro y más amplia la toma de decisiones para controlar el suceso, esta situación obedece a la complejidad de las grandes empresas donde los riesgos no se controlan con la simple delegación, control y organización, que en ocasiones facilitan la omisión de los controles por obedecer a la complejidad de los procesos productivos y organizacionales. (Demetrio Crespo, 2010) En este aspecto la posición de garante y el responsable penal del empresario exigen un completo análisis de la cultura empresarial respecto al cumplimiento de las funciones por parte del empresario, siendo necesario determinar si existe omisión en los controles y si esta omisión es la fuente del delito o contribuye a su realización, por parte de algunos subordinados que actuan con fines ilícitos dentro de la organización empresarial.

24 La impunidad la consideramos como el delito que no se castiga, siendo el daño o la acción ilícita el resultado de una conducta delictiva que merece sanción penal, sin que la reciba. 


\section{Referencias}

1. Abello Gual, J. (2011). La responsabilidad penal por el producto, problemas de la imputación, de autoría y participación. La Responsabilidad penal por el producto, problemas de la imputación, de autoría y participación (págs. 1-36). Bogotá: No publicada.

2. Acurio Del Pino, S. (21 de diciembre de 2010). http://www.oas.org/juridico/spanish/cyb_ecu_ delitos_inform.pdf. Obtenido de

3. Apelación contra Sentencia, C- 371 / 11 (Corte Constitucional 11 de mayo de 2011).

4. Bacigalupo, E. (2005). Delitos impropios de omisión. Madrid: Dykinson.

5. Bonilla, E. J. (2009). Introducción a la responsabilidad civil. IV curso de formación judicial para Magistrados y Jueces de la República. Bogotá: Consejo Superior de la Judicatura.

6. Cancio Meliá, M. (1998). Autoria y dominio del hecho en Derecho Penal. Dominio del hecho por dominio de voluntad en virtud de aparatos organizados de poder, pp. 34-35. Bogotá: Universidad Externado de Colombia № 20.

7. www.caracol.com.co. (17 de noviembre de 2008). http://www.caracol.com.co/nota. aspx?id=712301. Recuperado el 17 de mayo de 2011, de http://www.caracol.com.co/nota. aspx?id=712301: http://www.caracol.com.co/nota.aspx?id=712301

8. Colombia, C. d. (16 de diciembre de 2011). http://www.secretariasenado.gov.co/senado/ basedoc/ley/2000/ley_0599_2000.html. Recuperado el 9 de marzo de 2012, de http://www.secretariasenado.gov.co/senado/basedoc/ley/2000/ley_0599_2000.html:

9. Corona, N. A. (septiembre de 2002). http://www. siceditorial.com/ArchivosObras/obrapdf/ TA00892332005.pdf. Recuperado el 08 de febrero de 2001, de http://www.siceditorial.com/ ArchivosObras/obrapdf/TA00892332005.pdf:

10. Corte Suprema de Justicia, Radicación 14.124, Sentencia de única instancia (Corte Suprema de Justicia 21 de marzo de 2002).

11. Corte Suprema de Justicia, Radicado 14.124, Sentencia de única instancia (Corte Suprema de Justicia 21 de marzo de 2002).

12. Corte Suprema de Justicia, Casacion 25.696 Magistrado ponente Dr. Álvaro Orlando Pérez Pinzón (Corte Suprema de Justicia, Sala de Casación Pena 13 de julio de 2006).

13. Corte Suprema de Justicia, Sala de Casación Penal, Magistrado ponente Dr. Álvaro Orlando Pérez Pinzón., Proceso 22941 (Sentencia 20 de abril de 2006).

14. Corte Suprema de Justicia, Sala de Casación Penal, rad. M.P. María del Rosarío González (C.S.J., Sala de 23 de febrero de 2009). 
15. Davila, V. (5 de mayo de 2012). http://www.lafm.com.co/noticias/colombia/05-05-12/ asopartes-reporta-1100-denunci-11. Recuperado el 19 de mayo de 2012, de http://www.lafm. com.co/noticias/colombia/05-05-12/asopartes-reporta-1100-denunci-11: http://www.lafm.com.co/ noticias/colombia/05-05-12/asopartes-reporta-1100-denunci-11

16. Demanda de incostitucionalidad, Expediente D- 4930 (Corte Constitucional 1 de junio de 2004).

17. Demetrio Crespo, E. (14 de noviembre de 2010). http://www.ciidpe.com.ar/area1/posicion\%20de\%20garante\%20empresario.pdf. Recuperado el 19 de marzo de 2012, de http://www. ciidpe.com.ar/area1/posicion\%20de\%20garante\%20empresario.pdf:

18. Diaz y Garcia Conlledo, M. (2009). La Autoria en el derecho penal Colombiano. Bogotá: Leyer.

19. www.eltiempo.com. (14 de marzo de 2011). http://www.eltiempo.com/archivo/cronologico? $\% 60$ pagina $\% 60 \_=+1 \& \% 60 a \% 60=+1994 \& \% 60 \mathrm{~m} \% 60=+06 \& \% 60 \mathrm{~d} \% 60 \_=+03 \& a=2011$ \&pagin $a=4 \& m=09 \& d=09$. Recuperado el 9 de septiembre de 2011 , de http://www.eltiempo.com/archivo/ cronologico?\%60pagina\%60_=+1\&\%60a\%60_=+1994\&\%60m\%60_=+06\&\%60d\%60_=+03\&a= 2011 \&pagina $=4 \& m=09 \& d=09$ :

20. Feijoo Sánchez, B. (2009). Imputación objetiva en el Derechopenal económico y empresarial. Barcelona: Universidad Autonoma de Maddrid.

21. Gomés Velásquez, R. G. (2009). http://www.ejrlb.net/medios/docs/113/223_01 preacuerdos_y_negociaciones.pdf. Recuperado el 07 de febrero de 2011, de http://www.ejrlb. net/medios/docs/113/223_01_preacuerdos_y_negociaciones.pdf:

22. Gómez Velásquez, R. C. (2009). http://www.ejrlb.net/medios/docs/113/223_01 preacuerdos_y_negociaciones.pdf. Recuperado el 7 de febrero de 2011, de http://www.ejrlb.net/ medios/docs/113/223_01_preacuerdos_y_negociaciones.pdf:

23. Hernández Esquivel, J. A. (agosto de 2008). foros.uexternado.edu.co/ecoinstitucional/index. php/derpen/.../580. Recuperado el 21 de mayo de 2012, de foros.uexternado.edu.co/ecoinstitucional/index.php/derpen/.../580:

24. http://www.elmundo.com/portal/resultados/detalles/?idx=123426. (31 de julio de 2009). Recuperado el 06 de febrero de 2001, de http://www.elmundo.com/portal/resultados/ detalles/?idx=123426:

25. http://www.esmas.com/noticierostelevisa/internacionales/576274.html. (23 de octubre de 2006). $h$ ttp://www.esmas.com/noticierostelevisa/internacionales/576274.html, . Recuperado el 13 de agosto de 2011, de http://www.esmas.com/noticierostelevisa/internacionales/576274.html, :

26. Internacional, A. (s.f.). http://www2.amnistiainternacional.org/publica/muj_camp/capitulo3. pdf. Recuperado el 06 de febrero de 2011, de http://www2.amnistiainternacional.org/publica/ muj_camp/capitulo3.pdf:

27. Jacobo, P. E. (2003). Derecho Constitucional colombiano. Sexta Edición. Bogotá: Temis S.A. 
28. Jakobs, G. (1997). La responsabilidad oiva en el derecho penal. Buenos Aires: Ad Hoc S. R. L.

29. Jescheck, H.H. (1995). Tratado de Derecho Penal. Parte General, $4^{a}$ edición . Granada: Comares.

30. Consejo Superior de la Judicatura, C. S. (02 de enero de 2011). http://alcaldiademonteria. tripod.com/codigos/penal/prmrpnal.htm. Recuperado el 06 de febrero de 2011, de http://alcaldiademonteria.tripod.com/codigos/penal/prmrpnal.htm:

31. Lascano, C. J. (2001). Nuevas Formulaciones en las Ciencias Penales. Cordoba Argentina: Lerner.

32. LópezMesa, M. J., \& Félix, A. (2004). Tratado de la responsabilidad Civil, Tomo III. Buenos Aires: La Ley.

33. Márquez Cárdenas, Á. (2009). La autoría mediata en el derecho penal, Formas de instrumentalización. Bogotá: Doctrina y ley.

34. Martínez Pardo, V. J. (2010 de noviembre de 2010). La responsabilidad penal de las personas jurídicas. Valencia, , España.

35. Meini, I. (2003). Responsabilidad penal del empresario por los hechos cometidos por sus subordinados. Valencia España: Tirant lo Blanch.

36. Muñoz Díaz, N. (2011). Fenalco Presidencia Nacional. Recuperado el 21 de mayo de 2012, de Las mermas y su control interno: http://www.fenalco.com.co/contenido/1935/Las\%20 mermas\%20y\%20su\%20control\%20interno\%20\%E2\%80\%93\%20COSO

37. Navas Corona, A. (2002). Autoria y participación delicitiva. Bucaramanga: Sic, editorial limitada.

38. Nieto Marín, A. (2008). http://www.alfonsozambrano.com/doctrina_penal/resp_personas_ juridicas.pdf . Recuperado el 1 de junio de 2011, de http://www.alfonsozambrano.com/ doctrina_penal/resp_personas_juridicas.pdf : http://www.alfonsozambrano.com/doctrina_penal/ resp_personas_juridicas.pdf

39. Petrusanaky, c. C. (15 de febrero de 2009). http://www.slideshare.net/jcfdezmxmanag/ como-ha-cambiado-el-trabajo-del-gerente. Obtenido de http://www.slideshare.net/jcfdezmxmanag/como-ha-cambiado-el-trabajo-del-gerente: http://www.slideshare.net/jcfdezmxmanag/ como-ha-cambiado-el-trabajo-del-gerente

40. Portafolio. (12 de mayo de 2011). http://www.portafolio.co/economia/supersalud-intervino-ayer-la-eps-saludcoop. Recuperado el 12 de junio de 2011, de http://www.portafolio.co/ economia/supersalud-intervino-ayer-la-eps-saludcoop: http://www.portafolio.co/economia/ supersalud-intervino-ayer-la-eps-saludcoop

41. Reyes, r. M. (s.f.). http://www.unifr.ch/ddp1/derechopenal/anuario/an_1996_07.pd. Recuperado el 24 de agosto de 2011, de http://www.unifr.ch/ddp1/derechopenal/anuario/ an_1996_07.pd: 
42. Reyna Alfaro, L. (02 de octubre de 2007). http://www.teleley.com/revistaperuana/3reyna-68. pdf. Recuperado el 11 de junio de 2011, de http://www.teleley.com/revistaperuana/3reyna-68.pdf: http://www.teleley.com/revistaperuana/3reyna-68.pdf

43. Reyna Alfaro, L. M. (20 de agosto de 2009). http://www.teleley.com/ revistaperuana/3reyna-68.pdf . Recuperado el 08 de agosto de 2011, de http://www.teleley.com/ revistaperuana/3reyna-68.pdf : http://www.teleley.com/revistaperuana/3reyna-68.pdf consultado el 08 de agosto de 2011.

44. Roxin, C. (1997). Derecho Penal, Parte General, Tomo I. Madrid: Civitas.

45. Roxin, C., Jakobs, G., Schünemann, B., Frisch, W., \& Köhler, M. (2000). Sobre el Estado de la Teoría del Delito. Madrid: Civitas.

46. Sánchez Sánchez, R. (2005). Responsabilidad penal de las personas jurídicas. Bogotá: Ediciones Jurídicas Gustavo Ibáñez.

47. Semana.com. (23 de junio de 1997). http://www.semana.com/especiales/quiebra-cajavocacional/32672-3.aspx. Recuperado el 22 de junio de 2011, de

48. Sentencia, 843 / 99 (Corte Constitucional 27 de octubre de 1999).

49. Sentencia, radicado № 2006 - 009 M. P. Dr. Julio Alberto Lanchero (Tribunal Superior del Distrito Judicial de Cundinamarca, Sala Penal, 9 de julio de 2008).

50. Sentencia Casación , 12742 - 2003 (Corte Suprema de Justicia, Colombia, Mp. Dr. Alvaro Orlando Pérez 4 de abril de 2003).

51. Sentencia unica instancia, Proceso 15610. M.P., Dr. Fernando Arboleda Ripoll. (Corte Suprema de Justicia 26 de octubre de 2000).

52. Sentencia., radicado $N^{\circ} 25974$, M.P. Dra. María del Rosario González de Lemus (Corte Suprema de Justicia, Sala de Casación Penal 08 de agosto de 2007).

53. Suñez Tejera, Y. (qbril de 2012). Contribuciones a las ciencias sociales. Recuperado el 22 de mayo de 2012, de VALORACIONES TEÓRICO JURÍDICAS EN TORNO AL DELITO DE ESTAFA POR OMISIÓN : http://www.eumed.net/rev/cccss/20/yst.html

54. Tamayo Jaramillo, J. (1999). Tratado de la Responsabilidad Civil. Bogotá: Temis.

55. Teradillos Basoco, J. (1995). Derecho penal de la empresa. Madrid: Trotta.

56. Tiempo, E. (21 de marzo de 2011). http://m.eltiempo.com/economia/negocios/hay-plata-perolas-vas-siguen-a-paso-de-tortuga/9046751. Recuperado el 04 de febrero de 2011, de http://m. eltiempo.com/economia/negocios/hay-plata-pero-las-vas-siguen-a-paso-de-tortuga/9046751. 
57. Tiempo, E. (23 de noviembre de 2008). http://www.eltiempo.com/archivo/documento/ CMS-4683193. Recuperado el 18 de mayo de 2012, de http://www.eltiempo.com/archivo/documento/CMS-4683193: http://www.eltiempo.com/archivo/documento/CMS-4683193

58. Vanegas Franco, Alejandro. (2010). Levantamiento del velo corporativo. Panorama y perspectivas, el caso colombiano. Bogot'a: Universidad del Rosario. 